\title{
Efficient Planning of Energy Production and Maintenance of Large-scale Combined Heat and Power Plants
}

\author{
Georgios M. Kopanos ${ }^{\mathrm{a}, *}$, Oluwatosin C. Murele ${ }^{\mathrm{a}}$, Javier Silvente ${ }^{\mathrm{b}}$, Nurkhat Zhakiyev ${ }^{\mathrm{c}}$, Yerbol Akhmetbekov', \\ Damir Tutkushev ${ }^{\mathrm{d}}$, \\ ${ }^{a}$ Cranfield University, School of Water, Energy and Environment, Bedfordshire MK43 0AL, United Kingdom \\ ${ }^{\mathrm{b}}$ University College London, Centre for Process Systems Engineering, London WC1E 7JE, United Kingdom \\ ${ }^{c}$ National Laboratory Astana at Nazarbayev University, Energy, Ecology \& Climate Laboratory, Astana 010000, Kazakhstan \\ ${ }^{\mathrm{d}}$ Kazakhstan Utility Systems LLP, Karaganda 100012, Kazakhstan \\ *Corresponding author: g.kopanos@cranfield.ac.uk (Dr Georgios M. Kopanos)
}

\begin{abstract}
In this study, an efficient optimization framework is presented for the simultaneous planning of energy production and maintenance in combined heat and power plants, and applied in the largest coal-fired cogeneration plant of Kazakhstan. In brief, the proposed optimization model considers: (i) unit commitment constraints for boilers and turbines; (ii) minimum and maximum runtimes as well as minimum idle times for boilers and turbines; (iii) bounds on the operating levels for boilers and turbines within desired operating regions; (iv) extreme operating regions for turbines; (v) energy balances for turbines; (vi) total electricity and heat balances for satisfying the corresponding demands for electricity and heat (for each heat network); and (vii) maintenance tasks for units that must occur within given flexible time-windows. The minimization of the annual total cost of the cogeneration plant constitutes the optimization goal here, and it consists of startup and shutdown costs, fixed operating and fuel costs, maintenance costs, and penalties for deviation from heat and electricity demands, and penalties for turbines for operating outside the desired operating regions. An extensive data analysis of historical data has been performed to extract the necessary input data. In comparison to the implemented industrial solution that follows a predefined maintenance policy, the solutions derived by the proposed approach achieve reductions in annual total cost more than $21 \%$ and completely avoid turbines operation outside their desired operating regions. Our solutions report substantial reductions in startup/shutdown, fuel and fixed operating costs (about 85\%, 15\%, and 13\%, respectively). The comparative case study clearly demonstrates that the proposed approach is an effective means for generating optimal energy production and maintenance plans, enhancing significantly the resource and energy efficiency of the plant. Importantly, the proposed optimization framework could be readily applied to other cogeneration plants that have a similar plant structure.
\end{abstract}

Keywords: cogeneration; combined heat and power; energy planning; energy efficiency; maintenance; optimization

\section{Introduction}

Kazakhstan is a low-populated vast country that is the major financial player in Central Asia due to its huge reserves in major natural and mineral resources, such as coal, oil and gas, uranium, lead, chromium, zinc, copper, manganese, iron and gold. From 2000 to present, the country has experienced a remarkable economic growth and an increase in population from 15 to 18 million (Trading Economics, 2017; Ministry of National Economy of the Republic of Kazakhstan Committee, 2017), resulting in a significant increase in energy demand. The electricity demand in Kazakhstan has increased from 55 billion $\mathrm{kWh}$ in 2000 to 90.8 billion $\mathrm{kWh}$ in 2015, and it is estimated to reach 104.1 billion kWh in 2022 (KAZENERGY, 2015; Kazakhstan Electricity Grid Operating Company, 2015). Heat demand is also large in Kazakhstan due to its sharply continental climate with extremely cold large winter periods. In addition, the energy intensity of Kazakhstan's economy is twice as high as the average level of OECD countries, 
and 12\% higher than that of Russia. Kazakhstan adopted the "Energy Efficiency 2020" programme with the aim to reduce its energy intensity by $50 \%$ in 2050 (reference year is 2008).

Kazakhstan was ranked first in the world from the standpoint of intensity of carbon dioxide emissions per unit of GDP (International Energy Agency, 2014), and has set an ambitious target of 15-25\% economy wide reduction in greenhouse gas emissions by 2030 (reference year is 1990) within the framework of the Intended Nationally Determined Contribution under United Nations Climate Change Conference, COP21 (European Union External Action, 2015). The international commitment is primarily reinforced by the "Concept for Transition of the Republic of Kazakhstan to Green Economy" addressing the efficient management of the resources, developing a new national infrastructure and renovating the existing infrastructure. Kazakhstan Strategy 2050 aims at emissions reduction to $40 \%$ by 2050 through higher penetration of renewables and improvements in resource and energy efficiency (Green Economy, 2013). However, the current fossil fuel-friendly regulatory framework, and huge availability of conventional resources result in low-cost energy for both residential and industrial uses, making low-carbon solutions unattractive economically (Karatayev et al. 2016a; Karatayev. et al. 2016b). There is a clear need for strategic energy system planning incorporating environmental and economic trade-offs (Zeng et al., 2011). This should involve improvements in resource and energy efficiency in energy consuming and generation sectors, while acquiring economic benefits (Sarbassov et al., 2013). Efficient management strategies both in the investmentstrategic and operational level in the power sector are also essential (McGregor, 2017).

In Kazakhstan in 2015, coal-fired Combined Heat and Power (CHP) plants account for $81.6 \%$ of the total installed capacity for energy generation, followed by $10.2 \%$ of hydro, and $8.0 \%$ of gas (KAZENERGY, 2015). There are 111 CHP plants with total installed capacity of $21.3 \mathrm{GW}$ and available power of $17.5 \mathrm{GW}$ (McPherson et al., 2017). Most CHP plants are located in Pavlodar, Karaganda and East Kazakhstan due to a well-developed industrial infrastructure and associated steady electricity demand and high heat demand. The wide deployment of CHP plants in the power system of Kazakhstan was dictated by the Soviet central planning, as a convenient means for utilizing low-grade heat for district heating due to extremely cold climate and abundance of coal reserves. It is clear that cogeneration plants play a vital role in satisfying the energy demand in Kazakhstan, support the growth of the economy, and contribute to the well-being of the population especially during the long winter periods. For this reason, this study focuses on the management of the energy production and maintenance in such energy plants.

There are some works in the open literature that concentrated on the operational or maintenance planning of cogeneration and other energy systems. For instance, Abdollahi et al. (2016) developed a mathematical model for the optimal design and operational planning of energy networks based on CHP generators. Zulkafli and Kopanos (2016) presented an optimization framework for the operational and maintenance planning of production and utility systems under unit performance degradation and alternative resource-constrained cleaning policies. Silvente et al. (2015) proposed a rolling horizon optimization framework for the simultaneous energy supply and demand planning in microgrids. Bischi et al. (2014) presented a planning model for combined cooling, heat and power systems while Alipour et al. (2014) studied the short-term scheduling of CHP units under demand response programs. Hirvonen et al. (2014) proposed local sharing of cogeneration energy through individually prioritized controls for increased on-site energy utilization. Wakui et al. (2014) presented a mathematical programming model for cogeneration-based residential energy supply networks. Kopanos et al. (2013) developed mathematical models for the energy production planning of a network of residential CHP units, considering different network structures and analyzing alternative objective functions. Morales-España et al. (2013) and Ostrowski et al. (2012) tight mathematical models for the unit commitment problem, which could be considered relevant to the planning of cogeneration plants. Cristóbal et al. (2012) proposed a multi-objective optimization framework for the planning of coal-fired electricity production plants considering $\mathrm{CO}_{2}$ capture and preventive maintenance. $\mathrm{Li}$ and Nilkitsaranont (2009) presented a multiobjective optimization model for the modeling of the $\mathrm{CO}_{2}$ capture process based on of coal-fired electricity production plant. Alardhi et al. (2008) proposed a mathematical programming model for the preventive maintenance 
scheduling of multi-cogeneration plants. Detailed information on the maintenance planning industry along with insights to optimization and iteration methods to generate suitable maintenance plans can be found in Duffuaa et al. (1999).

It is observed that typically energy production and maintenance are considered individually or optimized sequentially, resulting in a need for optimization approaches that integrate these two major decision functions. For this reason, in this work, we develop a new optimization approach for the simultaneous planning of energy production and maintenance in cogeneration plants to bridge this research gap. The proposed optimization model is applied to an annual planning problem in the largest cogeneration plant of Kazakhstan to highlight that significant improvements achieved in the resource and energy efficiency of the plant along with major total cost reductions.

The paper is structured as follows. In Section 2, the problem under study is formally defined. The proposed optimization framework is then presented in Section 3. The case study considered is described in Section 4, followed by the presentation and discussion of the results in Section 5. Finally some concluding remarks are provided in Section 6.

\section{Problem Statement}

This study focuses on the simultaneous energy production and maintenance planning of the largest coal-fired combined heat and power plant in Kazakhstan, which is owned by KUS LLP and is located in Karaganda. The KUS CHP plant started its operations in 1976. Fig. 1 displays a simplified schematic representation of the layout of the KUS CHP plant, which is a typical CHP plant layout for other CHP plants in Kazakhstan as well as in other postSoviet states. As it can be seen in the figure, the KUS CHP plant consists of eight boilers (B1-B8), six multi-stage steam turbines (T1-T6), and two Reduction Cooling Units (RCUs). The network of boilers generates steam that through a major steam pipeline enters the network of turbines for electricity generation. The outlet heat flow of each turbine is used to satisfy the heat demand of the two heat networks connected to the CHP plant. RCUs could be used to overheat water up to $120^{\circ} \mathrm{C}$ when ambient temperature is below $-10^{\circ} \mathrm{C}$ and supply directly heat to the heat networks from the main steam pipeline, bypassing the turbines. Turbines T1-T3 are connected to the first heat network, and turbines T4-T6 are connected to the second heat network. The turbines usually operate under a 130 atm steam pressure and $555^{\circ} \mathrm{C}$ temperature mode, and their efficiencies are subject to the ambient temperature. The steam turbines of the plant offer the flexibility to extract steam from different stages of the turbine. This means that the heat and power generation are not strongly connected by a constant power-to-heat ratio as in the case of backpressure steam turbines. Instead, the turbines of the plant can operate within a feasible operating region. The produced electrical power and heat from each turbine depend on the steam inlet. The cross-linked steam pipeline structure adds another layer of flexibility to the system, since it reduces the dependence on individual boiler operations, maintenance and unexpected events. The KUS CHP plant is connected to the national electricity grid, from where it receives demands for electricity. Annual maintenance tasks for boiler and turbine units are predefined and follow a conservative policy to avoid potential damage of the equipment. Energy production planning is performed empirically by considering the known maintenance plan. In addition, significant material and energy resource consumption (i.e., coal, and electricity and heat) is required during the startup of boiler and turbine units. Currently, no proper optimization takes place during the generation of energy production and maintenance plans.

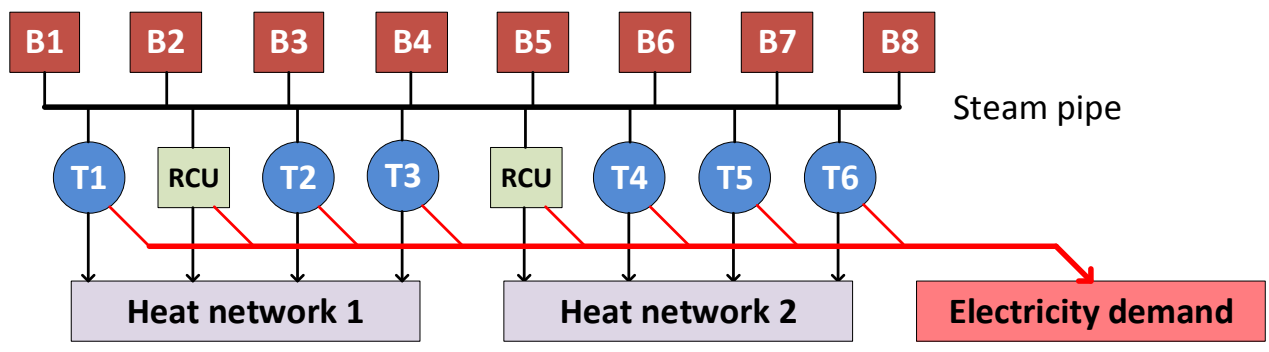


Fig. 1. KUS CHP plant layout (red boxes: boilers, blue circles: turbines, RCU: reduction cooling unit).

To improve the current industrial policy and demonstrate the opportunities for overall energy efficiency in the CHP plant, an optimization framework is developed for the simultaneous planning of energy production and maintenance for the KUS CHP plant, described above. It is necessary to provide a detailed problem description before presenting the proposed optimization model. The problem under study can be formally defined in terms of the following items:

- A time horizon $T$ that is divided into a number of equal-size time periods $t \in T$.

- A set of units $i \in I$ that consists of a number of boilers $i \in I^{B}$, and turbines $i \epsilon I^{T}$ with given efficiencies $\eta_{(i, t)}$.

- A set of heat networks $j \epsilon J$ (connected to the CHP plant) that each one has a dedicated RCU with given efficiency $\eta_{j}^{R C U}$.

- A given demand profile for electricity $\left(\zeta_{t}^{e l}\right)$ and given heat demand profiles for each heat network $\left(\zeta_{(j, t)}^{\text {heat }}\right)$.

- Given factors for internal electricity and heat requirements for the CHP plant ( $\beta_{t}^{E}$ and $\beta_{t}^{H}$, respectively).

- Given minimum runtimes $\left(\omega_{i}\right)$ and idle times $\left(\psi_{i}\right)$, for boiler and turbine units.

- Boiler units are characterized by maximum (minimum) heat generation levels $\theta_{(i, t)}^{\max }\left(\theta_{(i, t)}^{\min }\right)$ and heat losses factors $\operatorname{loss}_{i}$.

- Turbine units are characterized by maximum (minimum) electricity generation levels $\varepsilon_{(i, t)}^{\max }\left(\varepsilon_{(i, t)}^{\min }\right)$ within desired operating regions, and maximum outlet heat flows $\theta_{(i, t)}^{\operatorname{Tmax}}$.

- Given earliest and latest starting times $\left(\tau_{i}^{\min }\right.$ and $\left.\tau_{i}^{\max }\right)$, and durations $\left(v_{i}\right)$ and costs $\left(\kappa_{(i, t)}\right)$, for the maintenance tasks of boiler and turbine units.

- Given costs for startup $\left(\alpha_{(i, t)}\right)$, shutdown $\left(\varphi_{(i, t)}\right)$, fixed operation $\left(\pi_{(i, t)}\right)$, for boiler and turbine units,.

- Given fuel cost $\xi_{(i, t)}$ for each boiler and fuel calorific value $C q_{t}$.

- Given penalty terms for electricity purchases $\left(\lambda_{t}^{b u y}\right)$ and excessive electricity production $\left(\lambda_{t}^{e x}\right)$.

- Given penalty terms for heat purchases $\left(\mu_{(j, t)}^{b u y}\right)$ and heat disposal $\left(\mu_{(j, t)}^{e x}\right)$, for each heat network.

- Given penalty terms for operating a turbine in its lower or upper extreme region $\left(\rho_{(i, t)}^{-}\right.$or $\left.\rho_{(i, t)}^{+}\right)$.

For each time period, the administrator of the CHP plant needs to take main decisions regarding to:

- The operating status of each boiler and turbine unit (i.e., idle, startup, operating, shutdown).

- The maintenance status of each boiler and turbine unit (i.e., under maintenance or not).

- The operating regions of operating turbine units (i.e., desired or extreme operating regions).

- The operating level of each boiler and turbine unit.

- The outlet heat flow of each turbine unit.

- The heat flows that bypass the turbines (through the RCUs) and go directly to the heat networks.

- The deviation from the electricity demand (i.e., electricity purchases or excessive electricity production).

- The deviation from the heat demand of each heat network (i.e., heat purchases or heat disposal).

And all the above by considering the minimization of total cost that consists of costs related to startup, operation, shutdown and maintenance of boiler and turbine units as well as fuel costs along with penalties for deviation from heat and electricity demands.

\section{Optimization Framework}

In this section, a mathematical programming model is presented for the simultaneous planning of operational and maintenance tasks in combined heat and power plants as those described in Section 2. To facilitate the presentation 
of the proposed model, uppercase Latin letters for optimization variables and sets, and lowercase Greek letters for most of the parameters have been used. The description of the proposed optimization framework follows.

\subsection{Generation level bounds for boiler and turbine units and heat balance in the steam pipeline}

To model the generation levels for boiler and turbine units, we introduce operating binary variables $X_{(i, t)}$ that denote if a unit is operating (i.e., $X_{(i, t)}=1$ ) or not (i.e., $X_{(i, t)}=0$ ) during time period $t$. Constraints (1) provide lower $\left(\theta_{(i, t)}^{\min }\right)$ and upper $\left(\theta_{(i, t)}^{\max }\right)$ bounds on the heat generation level $Q_{(i, t)}^{B}$ for any boiler unit $i \in I^{B}$. In the same line,

constraints (2) impose lower $\left(\varepsilon_{(i, t)}^{\min }\right)$ and upper $\left(\varepsilon_{(i, t)}^{\max }\right)$ bounds on the electricity generation level $\left(E_{(i, t)}^{T}\right)$ for any turbine unit $i \in I^{T}$. In addition, the outlet heat from a turbine unit $Q_{(i, t)}^{\text {Tout }}$ should be below a maximum value $\theta_{(i, t)}^{\text {Tmax }}$, as modeled by constraints (3). Finally, constraints (4) represent the heat balance in the main steam pipeline. Nonnegative variables $H_{(j, t)}^{R C U}$ denote the associated heat sent to the reduction-cooling units (see Figure 1).

$$
\begin{aligned}
& \theta_{(i, t)}^{\min } X_{(i, t)} \leq Q_{(i, t)}^{B} \leq \theta_{(i, t)}^{\max } X_{(i, t)} \quad \forall i \in I^{B}, t \in T \\
& \varepsilon_{(i, t)}^{\min } X_{(i, t)} \leq E_{(i, t)}^{T} \leq \varepsilon_{(i, t)}^{\max } X_{(i, t)} \quad \forall i \in I^{T}, t \in T \\
& Q_{(i, t)}^{T o u t} \leq \theta_{(i, t)}^{T m a x} X_{(i, t)} \quad \forall i \in I^{T}, t \in T \\
& \sum_{i \in I^{B}}\left(1-\operatorname{loss}_{i}\right) Q_{(i, t)}^{B}=\sum_{i \in I^{T}} Q_{(i, t)}^{T i n}+\sum_{j \in J} H_{(j, t)}^{R C U} \quad \forall t \in T
\end{aligned}
$$

\subsection{Extreme operating regions for turbine units}

Constraints (2) define the desired operating region for each turbine unit through lower and upper bounds on the electricity generation level. This desired operating region ensures a stable operation for the turbine unit. However, in some cases operation out of this region may be allowed. In that case constraints (2) should be replaced by the following set of constraints:

$$
\begin{aligned}
& \Delta \varepsilon_{(i, t)}^{-} X_{(i, t)} \leq E_{(i, t)}^{T} \leq \Delta \varepsilon_{(i, t)}^{+} X_{(i, t)} \quad \forall i \in I^{T}, t \in T \\
& \varepsilon_{(i, t)}^{\min }-M\left(1-Y_{(i, t)}\right) \leq E_{(i, t)}^{T} \leq \varepsilon_{(i, t)}^{\max }+M\left(1-Y_{(i, t)}\right) \quad \forall i \in I^{T}, t \in T \\
& \Delta \varepsilon_{(i, t)}^{-}-M\left(1-Y_{(i, t)}^{-}\right) \leq E_{(i, t)}^{T}<\varepsilon_{(i, t)}^{\min }+M\left(1-Y_{(i, t)}^{-}\right) \quad \forall i \in I^{T}, t \in T \\
& \varepsilon_{(i, t)}^{\max }-M\left(1-Y_{(i, t)}^{+}\right)<E_{(i, t)}^{T} \leq \Delta \varepsilon_{(i, t)}^{+}+M\left(1-Y_{(i, t)}^{+}\right) \quad \forall i \in I^{T}, t \in T \\
& Y_{(i, t)}^{-}+Y_{(i, t)}+Y_{(i, t)}^{+}=X_{(i, t)} \quad \forall i \in I^{T}, t \in T
\end{aligned}
$$

Parameters $\Delta \varepsilon_{(i, t)}^{-}$and $\Delta \varepsilon_{(i, t)}^{+}$define the additional allowable operating regions lower than $\varepsilon_{(i, t)}^{\min }$ and higher than $\varepsilon_{(i, t)}^{\max }$ of the desired operating region, as shown in Fig. 2. Parameter $\mathrm{M}$ is a very large number. Binary variables $Y_{(i, t)}^{-}, Y_{(i, t)}$, and $Y_{(i, t)}^{+}$are introduced to identify if the turbine unit operates in the extreme lower operating region, the desired operating region, or the extreme upper operating region, respectively. These binary variables are then linked to the operating binary variable $X_{(i, t)}$ through the last line of constraints. In addition to these constraints, a penalty term needs to be added to the objective function of the optimization problem to penalize operation in extreme regions and thus favor operation within the desired operating region. 


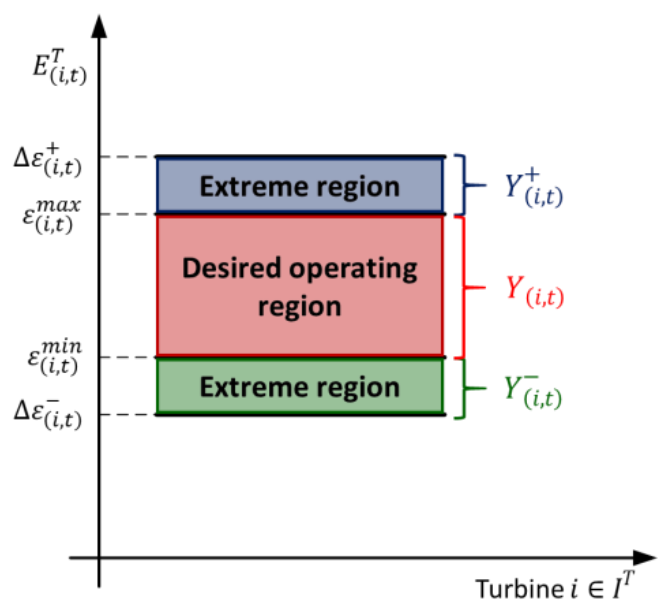

Fig. 2. Operating regions for turbine units.

\subsection{Electricity and heat balance in turbine and boiler units (energy demand)}

The heat balance for each turbine $i \in I^{T}$ is defined by considering the inlet heat to the turbine $Q_{(i, t)}^{T i n}$, the generated electricity $E_{(i, t)}^{T}$ from the turbine, the outlet heat $Q_{(i, t)}^{T o u t}$ from the turbine and its efficiency $\eta_{(i, t)}$, as given by:

$$
Q_{(i, t)}^{T i n}=\frac{E_{(i, t)}^{T}}{\eta_{(i, t)}}+Q_{(i, t)}^{T o u t} \quad \forall i \in I^{T}, t \in T
$$

Constraints (6) represent the electricity balance of the system for the satisfaction of the electricity demand. For every time period, this electricity balance ensures that the total electricity generated from the turbine units plus the electricity purchases $E_{t}^{b u y}$ are equal to the overall electricity demand $\zeta_{t}^{e l}$ (considering also the electricity demand of the internal system, given by factor $\beta_{t}^{E}$ ) plus the extra electricity generation $E_{t}^{e x}$. Constraints (7) represent the heat balance in each heat network for the satisfaction of its total heat demand. For each heat network and time period, the heat balance ensures that the outlet heat of all turbine units connected to the heat network $\left(i \in I_{j}^{T}\right)$ plus the total outlet heat of the reduction-cooling units and heat purchases $\left(H_{(j, t)}^{b u y}\right)$ are equal to the heat demand $\zeta_{(j, t)}^{\text {heat }}$ of the corresponding heat network plus the heat disposed $H_{(j, t)}^{e x}$.

$$
\begin{aligned}
& \sum_{i \in I^{T}} E_{(i, t)}^{T}+E_{t}^{b u y}=\left(1+\beta_{t}^{E}\right) \zeta_{t}^{e l}+E_{t}^{e x} \quad \forall t \in T \\
& H_{(j, t)}^{b u y}+\eta_{j}^{R C U} H_{(j, t)}^{R C U}+\sum_{i \in I_{j}^{T}} Q_{(i, t)}^{\text {Tout }}=\left(1+\beta_{t}^{H}\right) \zeta_{(j, t)}^{\text {heat }}+H_{(j, t)}^{e x} \quad \forall j \in J, t \in T
\end{aligned}
$$

If there are no external sources available for acquiring energy (electricity or heat), then the corresponding variables represent unsatisfied energy demands.

\subsection{Startup and shutdown action for boiler and turbine units}

For any boiler and turbine unit, constraints (8) and (9) determine startup and shutdown actions at each time point $t$ through the operating binary variables $X_{(i, t)}$ of any two consecutive time periods. Constraints (9) ensure that startup and shutdown actions cannot occur at the same time in any boiler or turbine unit $i$. For $t=0, X_{(i, 0)}$ is a known 
parameter that describes the initial state of the operational status for each unit just before the beginning of the time horizon considered.

$$
\begin{aligned}
& S_{(i, t)}-F_{(i, t)}=X_{(i, t)}-X_{(i, t-1)} \quad \forall i \in I, t \in T \\
& S_{(i, t)}+F_{(i, t)} \leq 1 \quad \forall i \in I, t \in T
\end{aligned}
$$

\subsection{Minimum run and idle times for boiler and turbine units}

Boiler and turbine units are subject to minimum run and idle periods ( $\omega_{i}$ and $\psi_{i}$, respectively) constraints, which are modeled by:

$$
\begin{gathered}
\sum_{t^{\prime} \geq \max \left\{1, t-\omega_{i}+1\right\}}^{t} S_{\left(i, t^{\prime}\right)} \leq X_{(i, t)} \quad \forall i \in I, t \in T \\
\sum_{t^{\prime} \geq \max \left\{1, t-\psi_{i}+1\right\}}^{t} F_{\left(i, t^{\prime}\right)} \leq 1-X_{(i, t)} \quad \forall i \in I, t \in T
\end{gathered}
$$

\subsection{Maximum runtimes for boiler and turbine units}

Constraints (12) impose an upper limit to the total number of time periods $t$ in which a unit $i$ has been continuously online since its last startup (i.e., maximum runtime $\delta_{i}$ ). To carry over relevant information from the past time horizon, initial state constraints (13) are introduced that consider the total number of time periods at the end of the previous time horizon in which unit $i$ has been continuously online since its last $\operatorname{startup}\left(\gamma_{i}\right)$.

$$
\begin{aligned}
& \sum_{t^{\prime} \geq \max \left\{1, t-\delta_{i}\right\}}^{t} X_{\left(i, t^{\prime}\right)} \leq \delta_{i} \quad \forall i \in I, t \in T \\
& \sum_{t^{\prime} \geq \max \left\{1, t-\delta_{i}+\gamma_{i}\right\}}^{t} X_{\left(i, t^{\prime}\right)} \leq \delta_{i}-\gamma_{i} \quad \forall i \in I, t \in T: t=\delta_{i}-\gamma_{i}+1, \gamma_{i}>1
\end{aligned}
$$

\subsection{Maintenance for boiler and turbine units: flexible time-windows policy}

Major maintenance tasks for boiler and turbine units are typically predefined (i.e., starting and finishing times of maintenance tasks are fixed) before the optimization of the energy production plan of the energy generation plant. The durations $v_{i}$ of maintenance tasks are generally known. In this study, we consider flexible maintenance tasks that should start (i.e., $W_{(i, t)}=1$ ) within a predefined time window $\left[\tau_{i}^{\min }, \tau_{i}^{\max }\right]$, and their actual starting times are additional decisions to be optimized. The following sets of constraints are used for boiler and turbine units that are subject to flexible time-window maintenance:

$$
\sum_{\substack{t \geq \tau_{i}^{\min } \\ t \in T}}^{\tau_{i}^{\max }} W_{(i, t)}=1 \quad \forall i \in I
$$




$$
X_{(i, t)}+\sum_{t^{\prime} \geq \max \left\{\tau_{i}^{\min }, t-v_{i}+1\right\}}^{\min \left\{\tau_{i}^{\max }, t\right\}} W_{\left(i, t^{\prime}\right)} \leq 1 \quad \forall i \in I, t \in T
$$

Predefined maintenance tasks (i.e., fixed starting time) could be also modeled by simply setting $\tau_{i}^{\min }=\tau_{i}^{\max }$.

\subsection{Objective function}

The optimization goal in this industrial-driven study is to minimize the annual total cost of the cogeneration plant, as given by equation (16). More specifically, the total cost considers startup and shutdown costs, fixed operating and fuel costs, maintenance costs, and penalties for deviation from heat and electricity demands, and penalties for turbines for operating outside the desired operating regions.

$$
\begin{array}{ll}
\min \operatorname{Cost}= & \text { Total cost (to be minimized) } \\
\sum_{t \in T} \sum_{i \in I}\left(\alpha_{(i, t)} S_{(i, t)}+\varphi_{(i, t)} F_{(i, t)}\right) & \text { Startup and shutdown costs for boiler and turbine units } \\
+\sum_{t \in T} \sum_{i \in I}\left(\pi_{(i, t)} X_{(i, t)}\right) & \text { Fixed operating costs for boiler and turbine units } \\
+\sum_{t \in T} \sum_{i \in I^{B}}\left(\frac{\xi_{(i, t)} Q_{(i, t)}^{B}}{\eta_{(i, t)} C q_{t}}\right) & \text { Heat generation costs for boilers (i.e., fuel cost) } \\
+\sum_{t \in T} \sum_{i \in I}\left(\kappa_{(i, t)} W_{(i, t)}\right) & \text { Maintenance costs for boiler and turbine units } \\
+\sum_{t \in T} \sum_{j \in J}\left(\mu_{(j, t)}^{b u y} H_{(j, t)}^{b u y}+\mu_{(j, t)}^{e x} H_{(j, t)}^{e x}\right) & \text { Penalties for deviation from heat demands } \\
+\sum_{t \in T} \sum_{i \in I^{T}}\left(\lambda_{t}^{b u y} E_{t}^{b u y}+\lambda_{t}^{e x} E_{t}^{e x}\right) &
\end{array}
$$

\section{Case Study}

The proposed optimization framework has been used to solve the simultaneous planning of operational and maintenance tasks in the KUS CHP plant, which is the largest coal-fired CHP plant of Kazakhstan with an installed power capacity of $670 \mathrm{MW}$ and a total thermal capacity equal to $1,058 \mathrm{Gcal} / \mathrm{h}$. The plant consists of eight boilers (B1-B8), six turbines (T1-T6) and two RCUs. The KUS CHP plant layout has been described in Section 2 (see Fig. 1). Each boiler unit consumes $70 \mathrm{ton} / \mathrm{h}$ of high-ash coal with low calorific value $\left(C q_{t}=3,980 \mathrm{kcal} / \mathrm{kg}\right)$. Coal cost is low $\left(\xi_{(i, t)}=\$ 6 /\right.$ ton $)$. Boilers B1 to B7 are of type 'BKZ-420-140' and have a lower and maximum heat generation level equal to 145.3 MW and 290.6 MW, respectively. Boiler B8 is of type 'HG-670/14y-YM20' and has a lower and maximum heat generation level equal to 231.3 MW and 464.9 MW, respectively. The heat losses coefficient due to the combustion loss/unburned fuel for all boiler units is equal to $2 \%$. Startup and shutdown costs for boilers are equal to $\$ 3,230$ and $\$ 2,422$, respectively. To specify the feasible operating regions for turbines, steam 
consumption relations between thermal output and electricity generation have been analyzed though extensive sets of historical data of the KUS CHP plant. The operating bounds for desired and extreme operating regimes as well as the maximum outlet heat flows for all turbines are given in Table 1. Startup and shutdown costs for turbines are equal to $\$ 916$ and $\$ 458$, respectively. The average monthly efficiency has been considered for each turbine. RCU efficiencies are equal to $10 \%$. For all boiler and turbine units, minimum runtimes are $\omega_{i}=2$ days, and minimum idle times are $\psi_{i}=1$ day.

Table 1. Operating levels bounds for desired and extreme operating regions and maximum outlet heat flows for turbines (MW).

\begin{tabular}{cccccc}
\hline Turbine & $\begin{array}{c}\text { min desired } \\
\text { regime } \varepsilon_{(i, t)}^{\text {min }}\end{array}$ & $\begin{array}{c}\text { max desired } \\
\text { regime } \varepsilon_{(i, t)}^{\max }\end{array}$ & $\begin{array}{c}\text { min extreme } \\
\text { regime } \\
\Delta \varepsilon_{(i, t)}^{-}\end{array}$ & $\begin{array}{c}\text { max extreme } \\
\text { regime } \\
\Delta \varepsilon_{(i, t)}^{+}\end{array}$ & $\begin{array}{c}\text { max outlet } \\
\text { heat flow } \\
\theta_{(i, t)}^{\text {Tmax }}\end{array}$ \\
\hline T1 & 66.0 & 110.0 & 55.0 & 115.0 & 203.4 \\
T2 & 66.0 & 110.0 & 22.0 & 110.0 & 203.4 \\
T3 & 66.0 & 110.0 & 38.0 & 115.0 & 203.4 \\
T4 & 66.0 & 110.0 & 34.0 & 120.0 & 203.4 \\
T5 & 72.0 & 120.0 & 48.0 & 135.0 & 218.5 \\
T6 & 66.0 & 110.0 & 33.0 & 110.0 & 197.6 \\
\hline
\end{tabular}

Table 2 includes the main data for the maintenance of boiler and turbine units along with the starting times of the implemented maintenance plant by the industry (maintenance plan for the KUS solution). There is also detailed information about the type of maintenance at each unit. More specifically, the following three types of maintenance are reported: Typical Maintenance (TM), Extended Maintenance (EM), and Major Overhaul (MO). In general, EM has a longer duration and higher cost than TM, and usually involves the replacement of important parts of the equipment (around 50\% replacement of parts). EM usually takes place in a unit once every 2-3 years. MO typically occurs in a unit once every 4-6 years and usually needs high maintenance durations. MO is the most expensive type of maintenance that involves the replacement of most parts of the equipment (around 90\% replacement of parts). Table 2 presents real data given by the KUS CHP plant.

Table 2. Maintenance data (including starting times for actual KUS solution).

\begin{tabular}{rrrrr}
\hline Unit & Type & $\kappa_{(i, t)}(\$)$ & $v_{i}$ (days) & $\tau_{i}^{\min }($ day $)$ \\
\hline B1 & TM & 20,000 & 29 & 125 \\
B2 & TM & 20,000 & 25 & 195 \\
B3 & MO & 153,729 & 88 & 107 \\
B4 & TM & 20,000 & 19 & 176 \\
B5 & MO & 111,966 & 74 & 224 \\
B6 & TM & 20,000 & 31 & 237 \\
B7 & TM & 20,000 & 11 & 161 \\
\hline T1 & TM & 10,000 & 20 & 20 \\
T2 & TM & 10,000 & 16 & 148 \\
T3 & MO & 41,815 & 88 & 205 \\
T4 & MO & 106,269 & 11 & 301 \\
T5 & EM & 30,415 & 41 & 161 \\
\hline
\end{tabular}

A total time horizon of one year divided in 365 daily time periods has been considered. Fig. 3 displays the annual demand profile for electricity and the annual heat demand profiles for the two heat networks connected to the KUS CHP plant. These are real energy demand data for year 2015. In addition, there are some electricity requirements for the use of internal equipment of the plant (e.g., coal crushers, pumps, compressors, blowers). These internal electricity requirements are given by $\beta_{t}^{E}=12.5 \%$; lower than that of other CHP plants in Kazakhstan (usually 
within 13-15\%). The internal heat requirements of the plant are given by $\beta_{t}^{H}=2 \%$. Finally, it should be mentioned that boiler B8 and turbine T6 have been installed in 2015 and they became available for limited operation (allowing to reach at most half of their installed capacity) only in the last month of the year. Remaining technical and cost related data cannot be provided due to confidentiality issues.

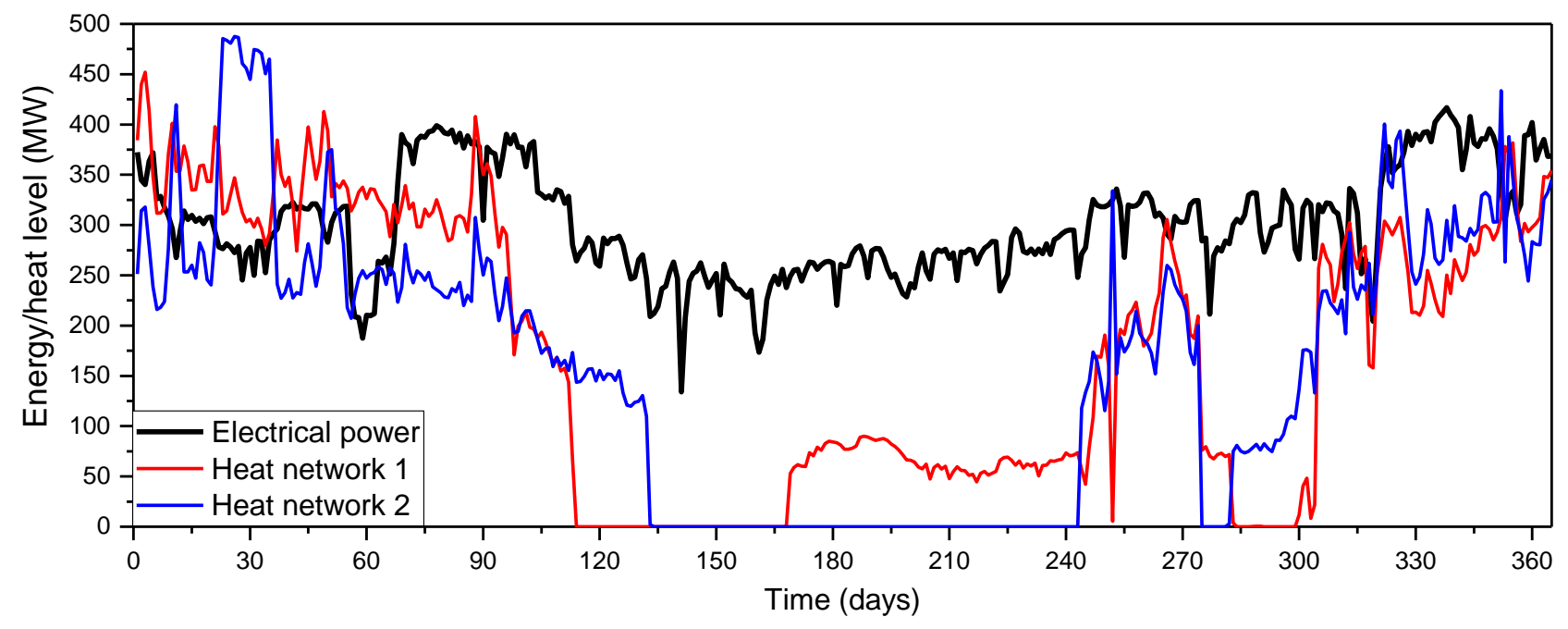

Fig. 3. Annual profiles for electricity demand and heat demand per heat network (MW).

\section{Results and Discussion}

In this part, for the above case study, a detailed comparison is presented among the solutions obtained by the proposed optimization approach and the solution implemented by the industry (i.e., KUS CHP plant). More specifically, we solve, analyze and compare the following set of solution approaches:

- KUS: energy production and maintenance plan implemented by the KUS CHP plant (industrial solution).

- OPT-1: optimized energy production through a fixed maintenance policy (i.e., same maintenance plan with KUS solution, thus fixed maintenance time-windows).

- OPT-2: optimized energy production and maintenance plan considering flexible time-windows of limited range (i.e., earliest and latest starting maintenance time one month before and after than the fixed time of the KUS solution).

- OPT-3: optimized energy production and maintenance plan considering completely flexible time-windows (i.e., maintenance can occur at any time within the year).

All optimization problems have been solved in GAMS/CPLEX 12.6 in an Intel(R) Core(TM) i7-6700 CPU under standard configurations and a zero optimality gap. Solutions are obtained in negligible computational times.

Fig. 4 and Fig. 5 display the maintenance plans for boilers and turbines for all solution approaches. Notice that the maintenance plan for OPT-1 is identical to that of KUS. It is observed that the maintenance tasks for all turbines in OPT-2 start and finish before those reported by KUS. The same trend is observed for the maintenance of most boilers, but B1 and B6. OPT-3 reports a maintenance plan that differs significantly from that of KUS. It is clear that the simultaneous optimization of maintenance and energy production generates maintenance plans that are considerably different than those obtained by following a predefined maintenance approach and solve the energy production planning in a second stage (i.e., KUS). 


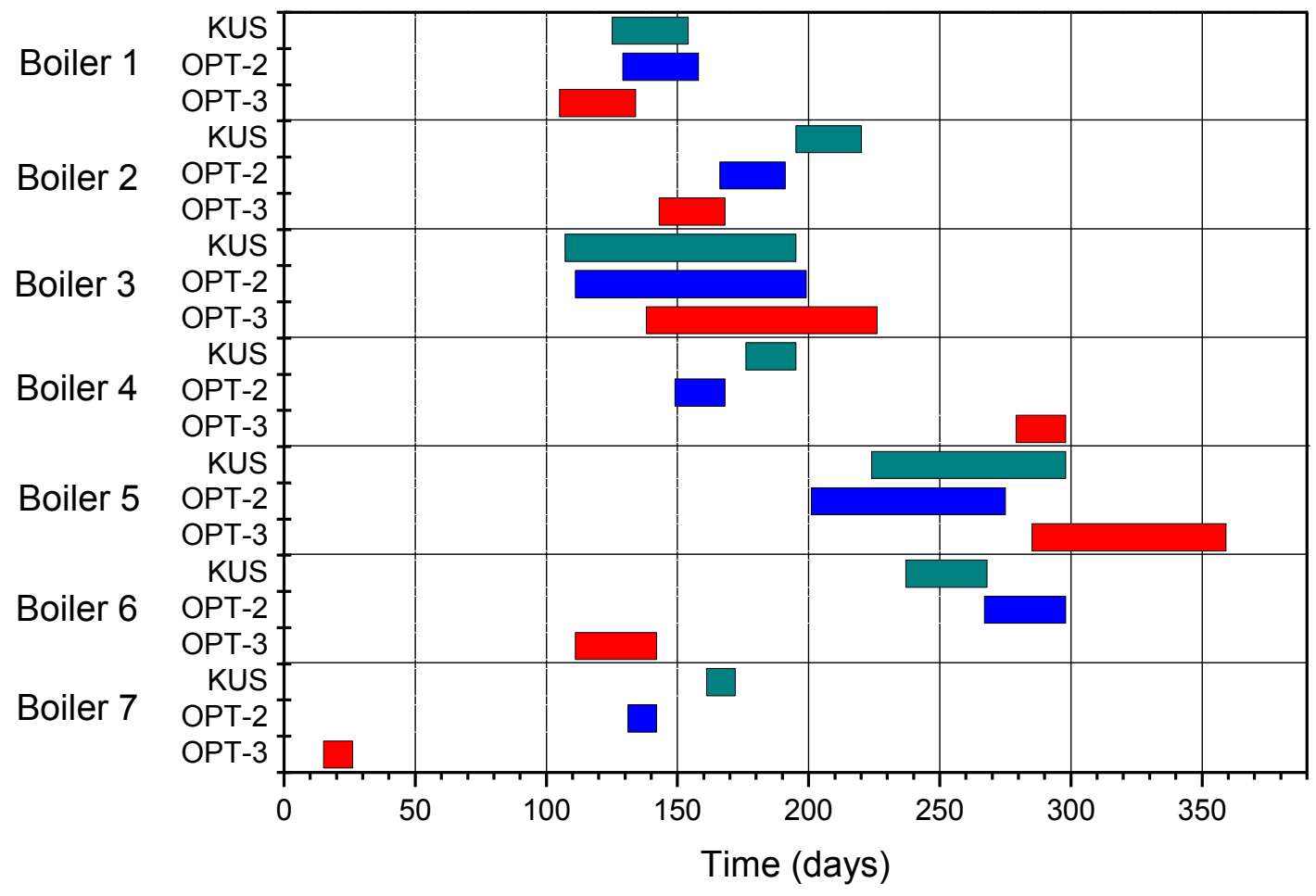

Fig. 4. Maintenance plans for boilers for all solution approaches.

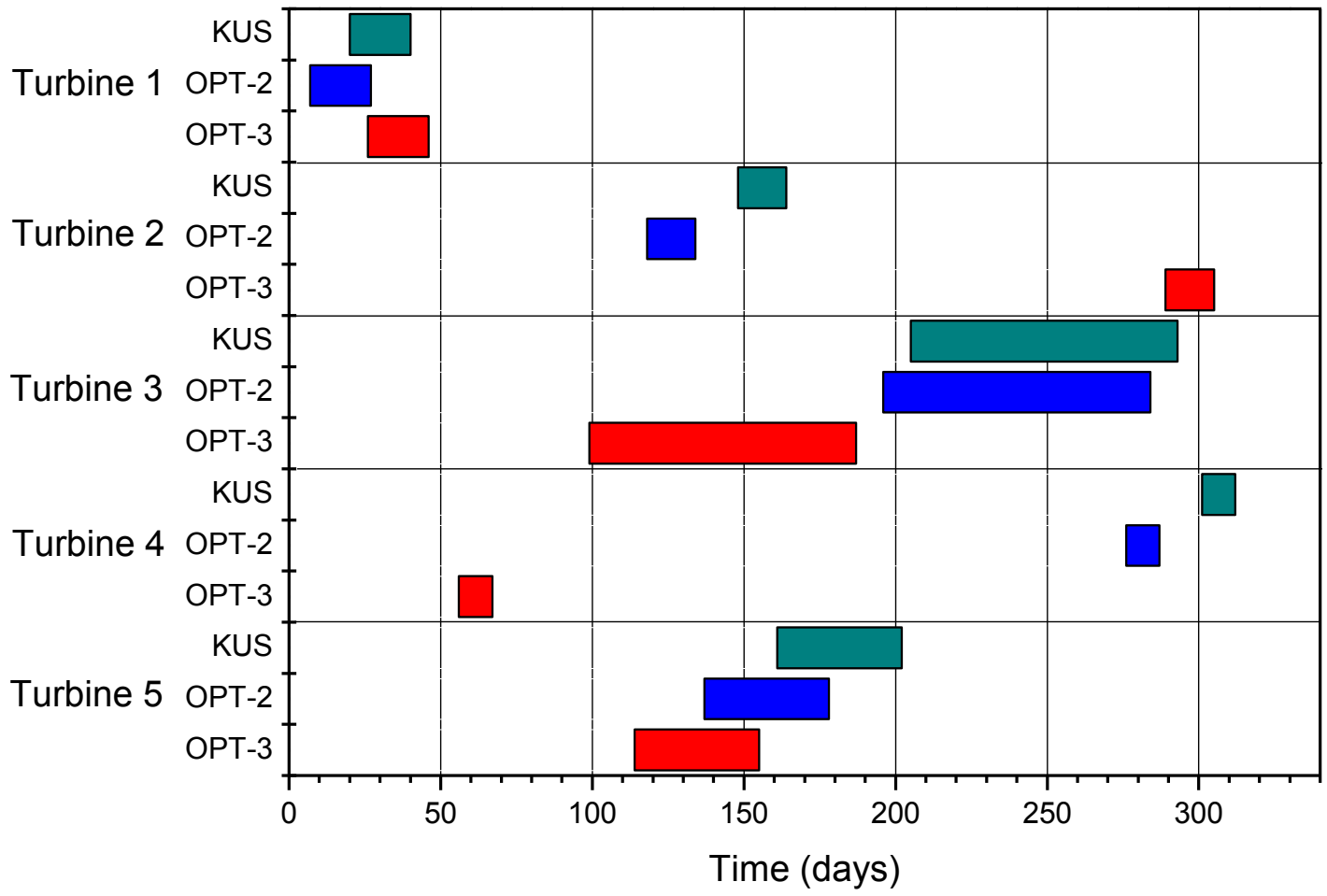

Fig. 5. Maintenance plans for turbines for all solution approaches. 
KUS SOLUTION

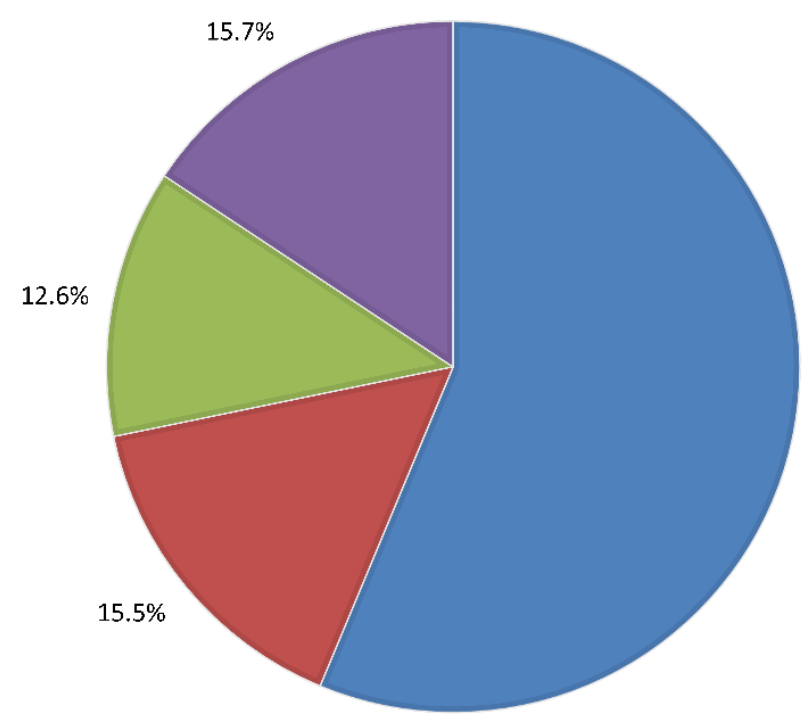

moiler fuel = Fixed operating - Startup/shutdown maintenance
OPTIMIZED SOLUTION: OPT-3

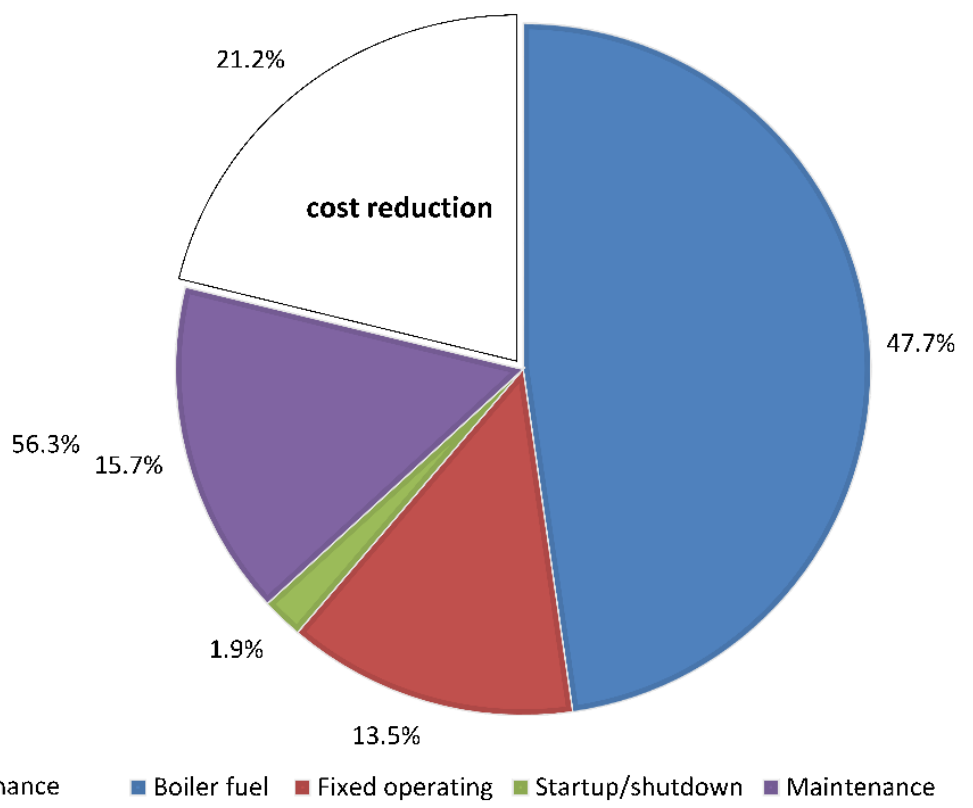

Fig. 6. KUS vs OPT-3: annual total cost breakdown (percentages).

Fig. 6 displays the annual total cost breakdown comparison between the industrial KUS solution and the solution obtained by our proposed approach OPT-3. A remarkable reduction in the annual total cost of $21.2 \%$ is reported by the optimization-based OPT-3 solution. Also, OPT-1 and OPT-2 report a reduction in total cost above $20 \%$ compared to that of KUS solution. Recall that the same maintenance tasks need to take place in all approaches, for this reason the maintenance cost contribution is the same for all solution approaches. As shown in Fig. 7, in comparison to the KUS solution, the OPT-3 solution results in a decrease in: (i) fuel costs by 15.2\%; (ii) fixed operating costs by $12.7 \%$; and (iii) startup/shutdown costs by $84.7 \%$. These show clearly that optimization approaches achieve to: (i) avoid unnecessary startups and shutdowns of boiler and turbine units; and (ii) decrease significantly the fuel consumption, and still fully satisfying the energy demands. 


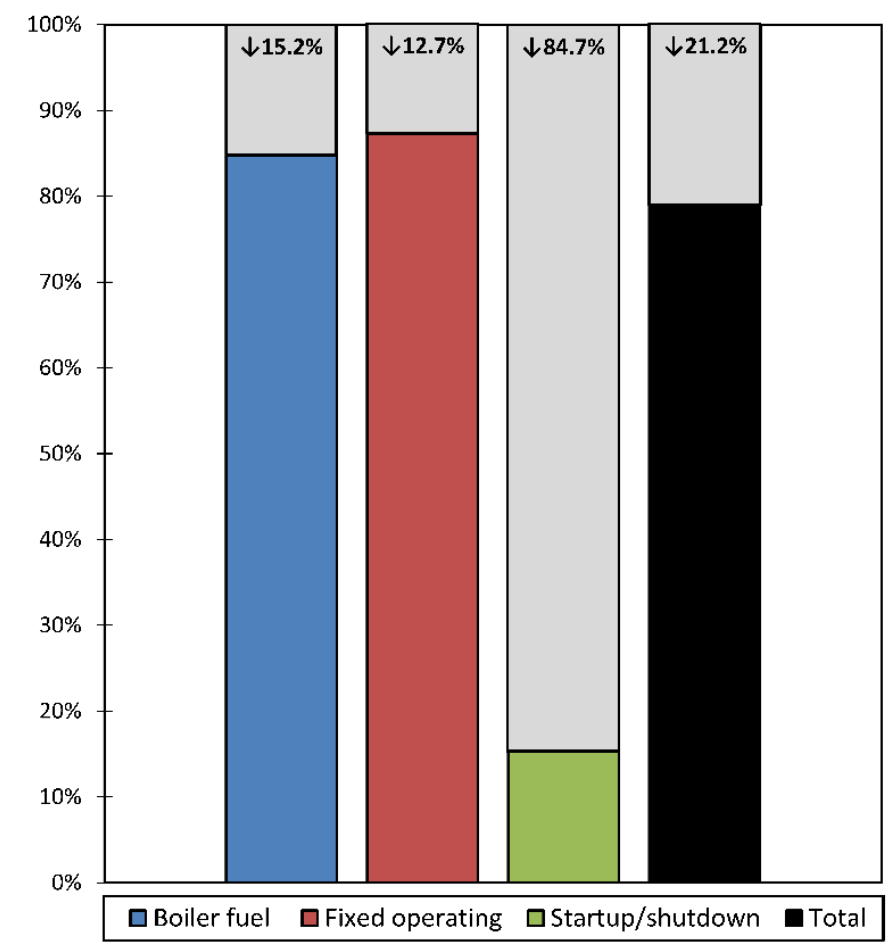

Fig. 7. KUS vs OPT-3: cost terms for OPT-3 compared to those of KUS solution.

Fig. 8 displays the aggregated total cost profiles for KUS, OPT-2 and OPT-3 solution approaches. It can be seen how the total cost difference increases over time among the optimized and the industrial solution.

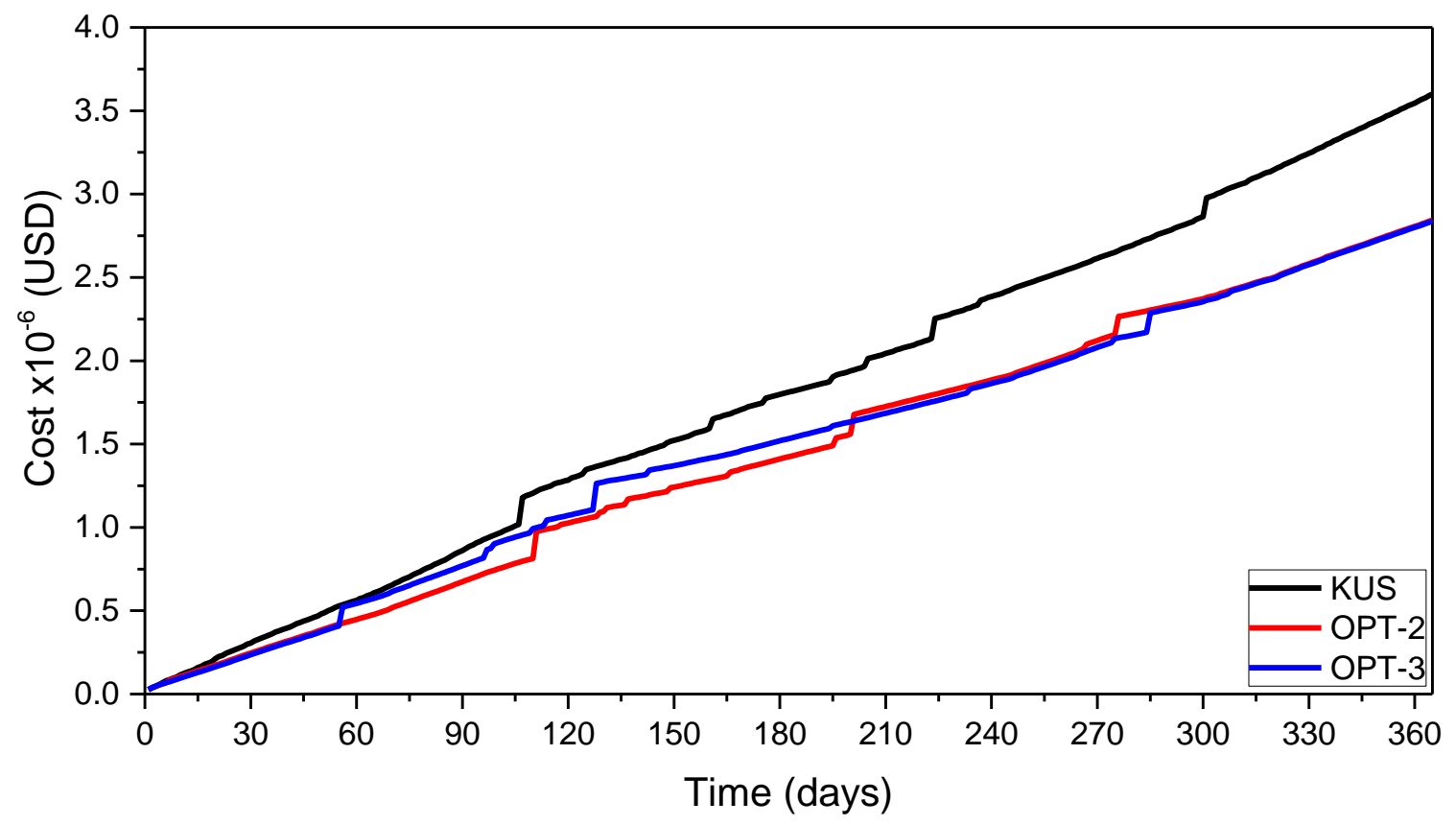

Fig. 8. Aggregated total cost profiles for KUS solution and optimized solutions OPT-2 and OPT-3.

The left part of Figs. 9a and 9b show the annual operating load profiles for all turbines for the KUS solution. These are normalized profiles with respect to the upper bound of the desired operating region of each turbine. Saying that, operating loads between $60 \%$ and $100 \%$ represent desired regions of operation while operating loads above 100\% 
or below $60 \%$ correspond to operation in extreme regions. In KUS solution, it can be seen that most turbines operate in extreme regions along the planning horizon considered. Especially, turbines 1, 3, 4 and 5 operate in the upper extreme region in many time periods. Turbines 2, 3, 4 and 5 operate in the lower extreme region for a very limited number of time periods. The right part of Figs. 9a and 9b shows a comparison of the annual operating load profiles for all turbines for the OPT-3 solution with respect to those of the KUS solution. More specifically, the figures on the right part of Figs. 9a and 9b display the profile of the deviation of the operating loads of OPT-3 having as a reference the operating loads reported by the KUS solution (i.e., figures on the left part). The red line on the figures on the right part corresponds to the KUS solution operating load levels shown on the corresponding figures on the left. Energy demands are completely satisfied in both solution approaches. The most significant fact is that OPT-3 solution does not report operation of turbines in extreme regions at any time period. Operation in extreme regions affects importantly the efficiency and the performance degradation of the turbine, increase the possibility of mechanical damage, and in the longer-term could reduce considerably the life-time of the equipment. On average, OPT-3 reports lower total operating loads throughout the planning horizon considered, contributing to the reduction in fuel consumption. Recall that turbine 6 is available only in the last month of the year and can operate in half its maximum capacity. OPT-3 solution prefers not to operate at all turbine 6 , since the electricity demand in that month can be met by the other turbines.
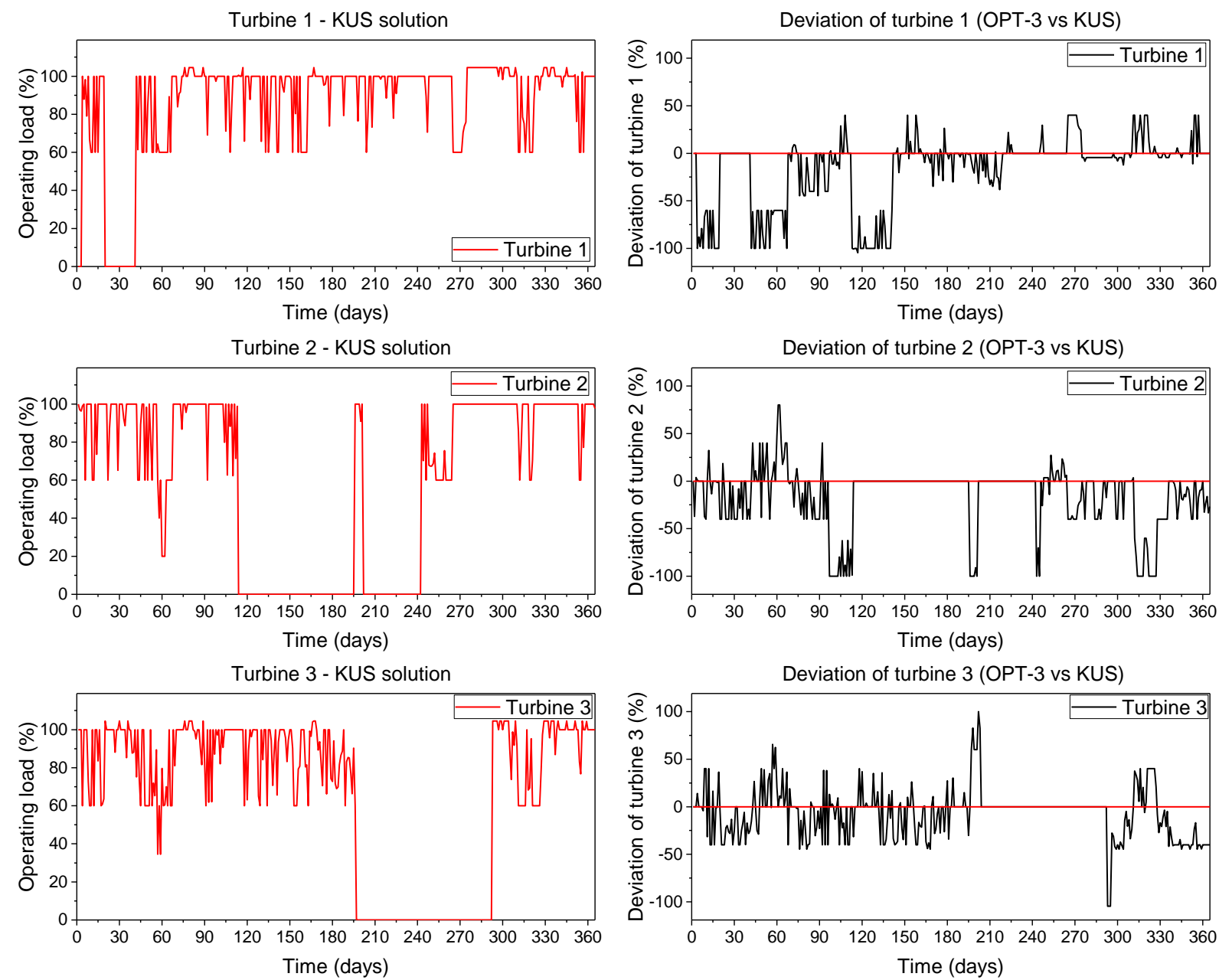

Fig. 9a. KUS vs OPT-3: Turbines 1 to 3. Normalized operating load profile for KUS solution (figures on the left), and operating load deviation profile for OPT-3 from KUS solution (figures on the right). 

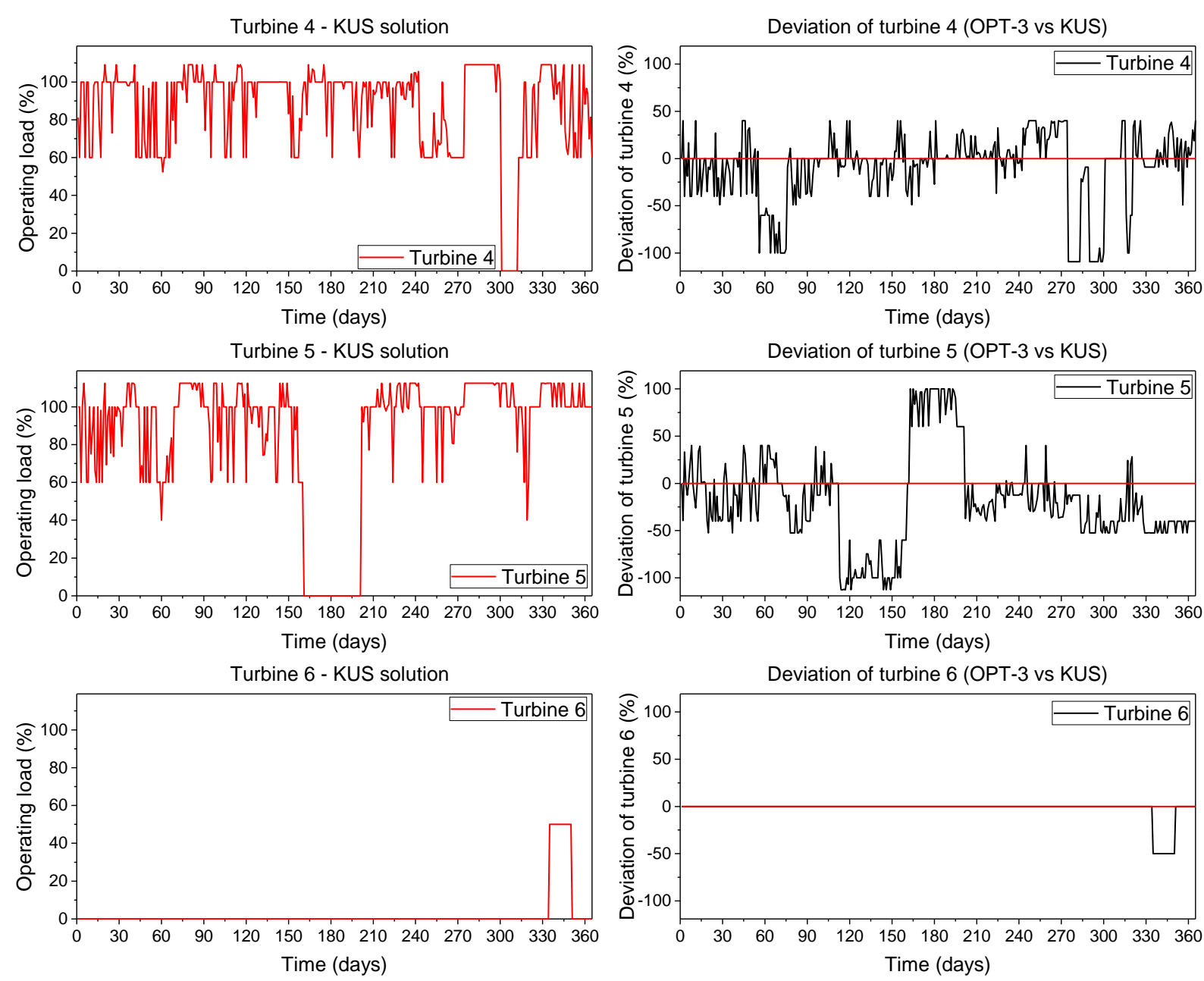

Fig. 9b. KUS vs OPT-3: Turbines 4 to 6. Normalized operating load profile for KUS solution (figures on the left), and operating load deviation profile for OPT-3 from KUS solution (figures on the right).

In the same line with Figs. 9a and 9b, Figs. 10a and 10b display the relevant operating load information for all boiler units along with a comparison of them between the KUS and OPT-3 solutions. Boiler 8 is available only in the last month of the year, but it is not used in any of the two solutions, and for this reason it is not presented in those figures. The left part of Figs. 10a and 10b display the annual operating load profiles for all boiler for the KUS solution, normalized profiles with respect to the maximum heat generation level of each boiler. The figures on the right part of Figs. 10a and 10b display the profile of the deviation of the operating loads of the OPT-3 solution having as a reference the operating loads reported by the KUS solution (i.e., figures on the left part). The red line on the figures on the right part corresponds to the KUS solution operating load levels shown on the corresponding figures on the left. It is observed that boilers 1 and 7 are not used in OPT-3 solution as much as in KUS. This is basically due to the associated technical characteristics and operating costs for these boilers, as also confirmed by the industry. Important deviations on the operating levels for boiler 2 and 3 are observed between the KUS and the OPT-3 solution, but overall heat generation levels are comparable. In general, the OPT-3 solution reports higher overall heat generation levels for boilers 4 to 6 in comparison to those in the KUS solution. 

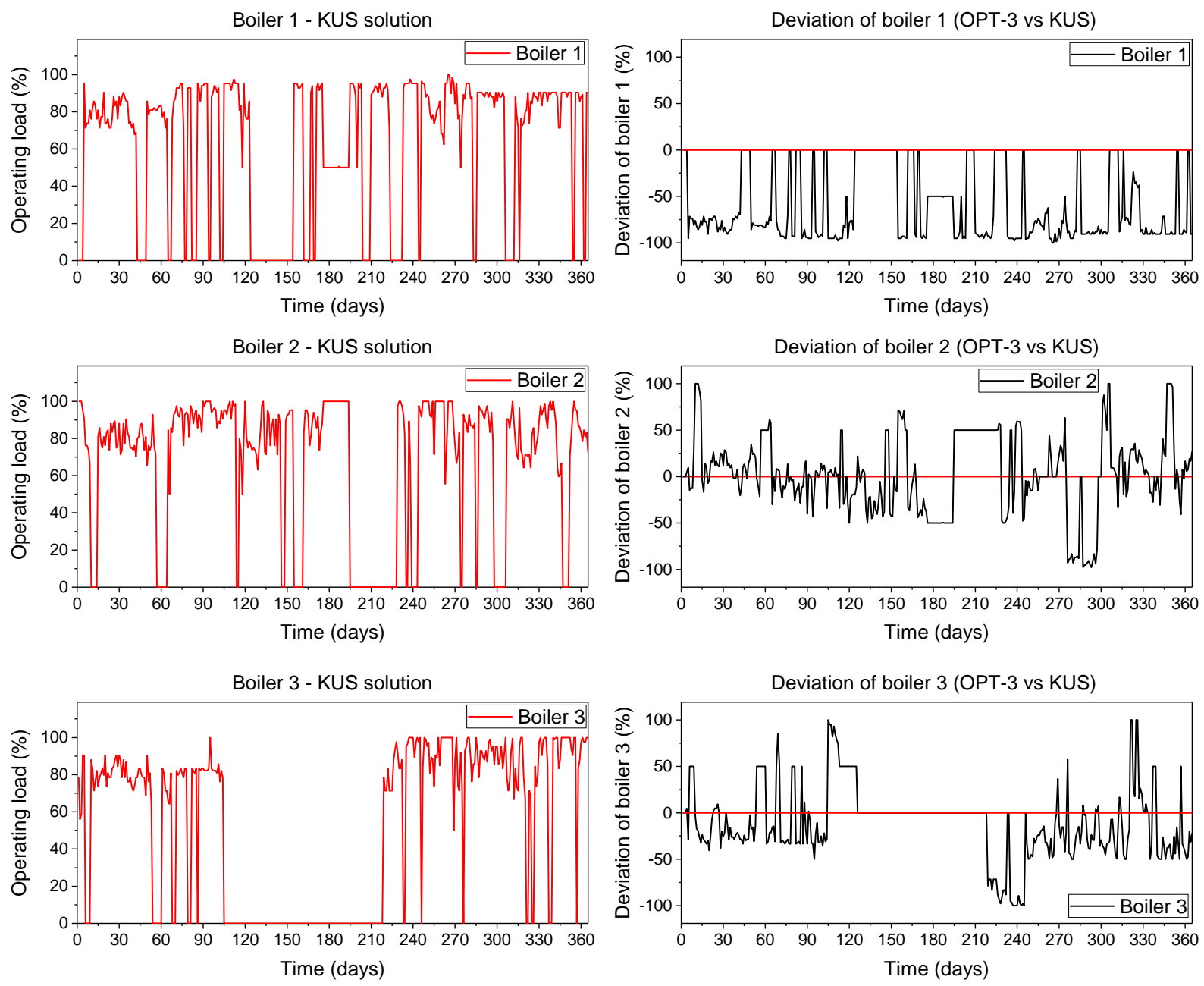

Fig. 10a. KUS vs OPT-3: Boilers 1 to 3. Normalized operating load profile for KUS solution (figures on the left), and operating load deviation profile for OPT-3 from KUS solution (figures on the right). 

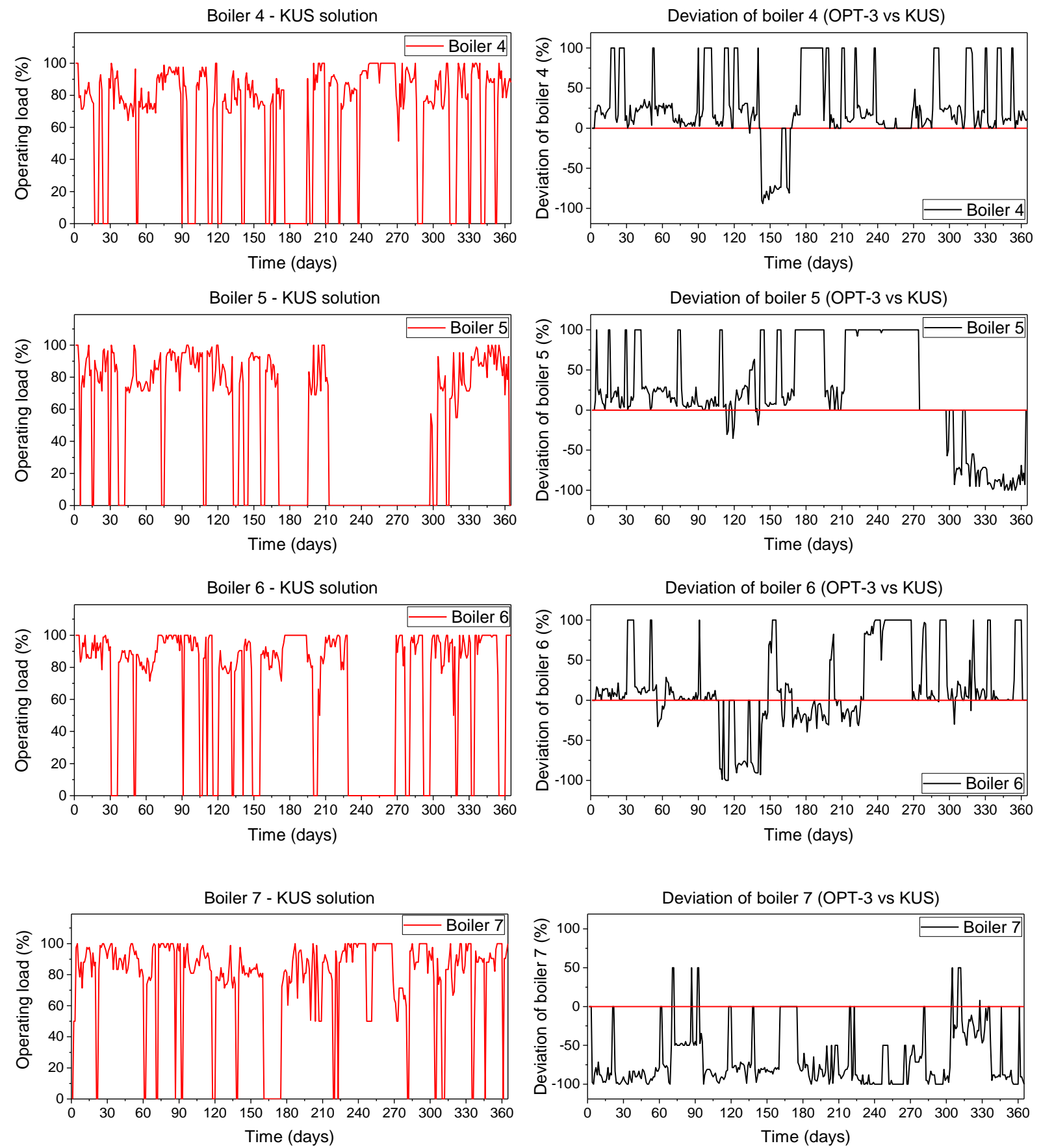

Fig. 10b. KUS vs OPT-3: Boilers 4 to 7. Normalized operating load profile for KUS solution (figures on the left), and operating load deviation profile for OPT-3 from KUS solution (figures on the right).

All results presented here have been validated by the industry, and it has been recognized that the proposed optimization framework can generated energy production and maintenance plans that result in remarkable reductions in total costs and enhanced energy efficiency of the cogeneration plant. The proposed approach constitutes a systematic way for the better coordination of energy production and maintenance tasks that could be the main core of an optimization-based decision support tool enclosed within a user-friendly graphical user interface to be used directly by the industry. 


\section{Concluding Remarks}

In this work, a general optimization model for the integrated planning of energy production and maintenance has been developed and applied in a case study of the largest coal-fired combined heat and power plant of Kazakhstan. An extensive data analysis of historical data has been performed to extract the necessary input data. The case study considered demonstrated clearly the significant benefits of the proposed optimization-based approach. More specifically, the solutions obtained by the proposed approach achieve reductions in annual total cost more than $21 \%$ and totally avoid turbines operation outside their desired operating regions, in comparison to the industrial solution. Additionally, our solutions report substantial reductions in startup/shutdown, fuel and fixed operating costs, and improved energy efficiency of the cogeneration plant. Overall, the comparative case study has demonstrated clearly that the proposed approach is a much more effective means for generating optimal energy production and maintenance plans than the current industrial policy. Notice that the proposed optimization model could be readily applied to other cogeneration plants that follow a similar plant structure. Currently, extensive data analysis is taking place with the purpose to derive suitable performance degradation and recovery models for the boilers and turbines, and thus result in a maintenance strategy that considers explicitly the condition of these major equipment.

\section{Nomenclature}

\section{Indexes / Sets}

$i \in I \quad$ units (boilers and turbines)

$j \in J \quad$ heat networks (note: a reduction cooling unit is associated to each heat network)

$t, t^{\prime} \in T \quad$ time periods

$i \in I^{B} \quad$ set of boiler units

$i \in I^{T} \quad$ set of turbine units

$i \in I_{j}^{T} \quad$ set of turbine units $i \epsilon I^{T}$ that are connected to heat network $j$

\section{Binary Variables}

$X_{(i, t)} \quad=1$, if unit $i$ operates during time period $t$

$Y_{(i, t)} \quad=1$, if turbine unit $i \epsilon I^{T}$ operates during time period $t$ within the desired operating region

$Y_{(i, t)}^{+} \quad=1$, if turbine unit $i \epsilon I^{T}$ operates during time period $t$ within the upper extreme operating region

$Y_{(i, t)}^{-} \quad=1$, if turbine unit $i \in I^{T}$ operates during time period $t$ within the lower extreme operating region

$S_{(i, t)} \quad=1$, if unit $i$ starts operating at the beginning of time period $t$

$F_{(i, t)} \quad=1$, if unit $i$ stops operating at the beginning of time period $t$

$W_{(i, t)} \quad=1$, if the maintenance task of unit $i$ starts at the beginning of time period $t$

\section{Continuous Variables (non-negative)}

$E_{(i, t)}^{T} \quad$ electricity generation level of turbine unit $i \in I^{T}$ in time period $t$

$E_{t}^{\text {buy }} \quad$ electricity purchases in time period $t$ (or unsatisfied electricity demand)

$E_{t}^{e x} \quad$ excessive electricity generation in time period $t$

$H_{(j, t)}^{b u y}$

$H_{(j, t)}^{e x}$

$H_{(j, t)}^{R C U}$

$Q_{(i, t)}^{B}$

$Q_{(i, t)}^{\text {Tin }}$

$Q_{(i, t)}^{\text {Tout }}$ heat purchases for heat network $j$ in time period $t$ (or unsatisfied heat demand)

excessive heat generation for heat network $j$ in time period $t$ direct heat flow to heat network $j$ (via its associated reduction cooling unit) in time period $t$ heat generation level of boiler unit $i \epsilon I^{B}$ in time period $t$ inlet heat flow to turbine $i \epsilon I^{T}$ in time period $t$ outlet heat flow from turbine $i \epsilon I^{T}$ in time period $t$ 


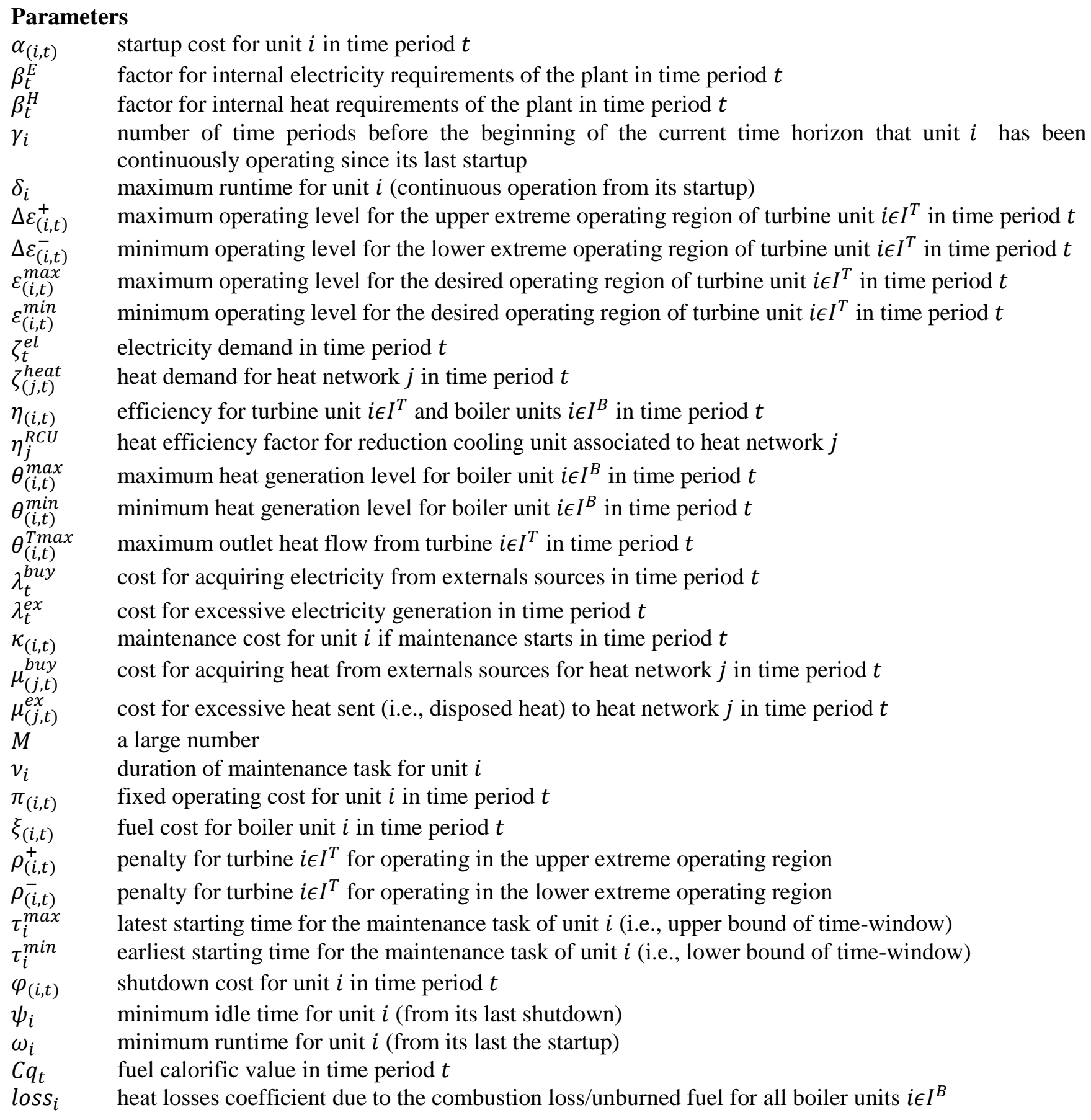

\section{Acknowledgements}

Financial support from the Royal Academy of Engineering under the project "Increase of energy efficiency in Combined Heat and Power (CHP) plants using state-of-the-art optimization methods: Case study in LLP KUS" (Ref: IAPP\1516\115) is gratefully acknowledged. O.C. Murele would like to also thank the Petroleum Technology Development Fund, Nigeria (PTDF/ED/PHD/MOC/876/16) for the PhD sponsorship. 


\section{References}

Abdollahi, E., Wang, H., Lahdelma, R. (2016) An optimization method for multi-area combined heat and power production with power transmission network. Applied Energy 168, 248-256.

Alardhi, M., Labib, A.W. (2008) Preventive maintenance scheduling of multi-cogeneration plants using integer programming. Journal of the Operational Research Society 59, 503-509.

Alipour, M., Zare, K., Mohammadi-Ivatloo, B. (2014) Short-term scheduling of combined heat and power generation units in the presence of demand response programs. Energy, 71, 289-301.

Bischi, A., Taccari, L., Martelli, E., Amaldi, E., Manzolini, G., Silva, P., Campanari, S., Macchi, E. (2014) A detailed MILP optimization model for combined cooling, heat and power system operation planning. Energy 74 (C), 12-26.

Cristóbal, J., Guillén-Gosálbez, G., Jiménez, L., Irabien, A. (2012) Multi-objective optimization of coal-fired electricity production with CO2 capture. Applied Energy 98, 266-272.

Duffuaa, S.O., Raouf, A., Campbell, J. D. (1999) Planning and control of maintenance systems. John Willey and Son, New York.

European Union External Action, (2015).

http://eeas.europa.eu/archives/delegations/kazakhstan/press_corner/all_news/news/2015/20151012_en.htm

(accessed September 2017)

Green Economy (2013) Concept for the transition of the Republic of Kazakhstan to a green economy, approved by Decree \#557 of the President of the Republic of Kazakhstan.

Hirvonen, J., Kayo, G., Hasan, A., Siren, K. (2014) Local sharing of cogeneration energy through individually prioritized controls for increased on-site energy utilization. Applied Energy 135, 350-363.

International Energy Agency (2014) Kazakhstan: Indicators for 2014.

Karatayev, M., Clarke, M.L. (2016a) A review of current energy systems and green energy potential in Kazakhstan. Renewable and Sustainable Energy Reviews 55, 491-504.

Karatayev, M., Hall. S., Kalyuzhnova, Y., Clarke, M.L. (2016b) Renewable energy technology uptake in Kazakhstan: Policy drivers and barriers in a transitional economy. Renewable and Sustainable Energy Reviews 66, $120-136$.

Kazakhstan Electricity Grid Operating Company (2015), Annual Report.

KAZENERGY 2015. The National Energy Report 2015.

Kopanos, G.M., Georgiadis, M.C., Pistikopoulos, E.N. (2013) Energy production planning of a network of micro combined heat and power generators. Applied Energy 102, 1522-1534.

Li, Y.G., Nilkitsaranont, P. (2009) Gas turbine performance prognostic for condition-based maintenance. Applied Energy 86, 2152-2161.

MacGregor, J. (2017) Determining an optimal strategy for energy investment in Kazakhstan. Energy Policy 107, 210-224.

McPherson, M., Harvey, L.D., Karney, B. (2017) System design and operation for integrating variable renewable energy resources through a comprehensive characterization framework. Renewable Energy 113, 1019-1032. 
Ministry of National Economy of the Republic of Kazakhstan (2017). http://stat.gov.kz and http://economy.gov.kz/en/ (last accessed December 2017)

Morales-España G., Latorre J.M., Ramos A. (2013) Tight and Compact MILP Formulation of Start-Up and ShutDown Ramping in Unit Commitment, IEEE Transaction on Power Systems 28, 1288-1296.

Ostrowski J., Anjos M., Vannelli A. (2012) Tight mixed integer linear programming formulations for the unit commitment problem. IEEE Transaction on Power Systems 7, 39-46.

Sarbassov, Y., Kerimray, A., Tokmurzin, D., Tosato, G., Miglio, R. (2013) Electricity and heating system in Kazakhstan: Exploring energy efficiency improvement paths. Energy Policy 60, 431-444.

Silvente, J., Kopanos, G.M., Pistikopoulos, E.N., Espuña, A. (2015) A rolling horizon optimization framework for the simultaneous energy supply and demand planning in microgrids. Applied Energy 155, 485-501.

Trading Economics (2017). https://tradingeconomics.com/kazakhstan/gdp (last accessed October 2017)

Wakui, T., Kinoshita, T., Yokoyama, R. (2014) A mixed-integer linear programming approach for cogenerationbased residential energy supply networks with power and heat interchanges. Energy 68, 29-46.

Zeng, Y., Cai, Y., Huang, G., Dai, J. (2011) A review on optimization modeling of energy systems planning and GHG emission mitigation under uncertainty. Energies 4, 1624-1656.

Zulkafli NI., Kopanos, G.M. (2016) Planning of production and utility systems under unit performance degradation and alternative resource-constrained cleaning policies. Applied Energy 183, 577-602. 